\title{
The relationship of the quality of life and burden of informal caregivers of patients with cancer in Lima, Peru
}

\author{
Maria Isabel Peñarrieta de Córdova ${ }^{* 1}$, Reyda Canales ${ }^{2}$, Sherin Krederdt ${ }^{2}$, Tranquilina Gutiérrez-Gómez ${ }^{1}$, Rodrigo \\ Leon Hernandez ${ }^{3}$ \\ ${ }^{1}$ Universidad Autónoma de Tamaulipas, Mexico \\ ${ }^{2}$ Universidad Norbert Wiener, Lima Peru \\ ${ }^{3}$ Catedrático CONACYT/Universidad Autónoma de Tamaulipas, Mexico
}

Received: December 21, 2015

Accepted: February 24, 2016

Online Published: March 22, 2016

DOI: $10.5430 /$ jnep.v6n8p36

URL: http://dx.doi.org/10.5430/jnep.v6n8p36

\begin{abstract}
Objective: To evaluate quality of life the Informal cancer (IC) patients' caregivers offer to relatives suffering from cancer and to determine their relation with the IC work overload.

Methods: The study was correlational cross-sectional design. The convenience sample included 164 caregivers of relatives diagnosed with cancer who are receiving chemotherapy treatment in a General Hospital in Lima, Peru. The instrument of "Zarit Rating Scale”, and The Medical Outcomes Study Short Form, version 2(SF-36v2)SF36 were used, along with questions on sociodemographic data to the caregiver and the cancer patient. Descriptive statistics and Spearman's $\rho$ were used.

Results: The $85 \%$ of IC referred to perform this role for more than three months, while $15 \%$ from one to two months. More than a half $(60 \%)$ cohabited with the patient. Most $(74 \%)$ had greater burden. The areas of highest percentages of overload indicated fear and dependency of the IC towards the relatives diagnosed. The results on quality of life presented an average below $60 \%$ in social functions, vitality, mental health and general health. The results of significant correlation between quality of life and overload are: general health, social functioning and pain $(p: .01-.02)$.

Conclusions: The results described the caregivers group of people with cancer as a vulnerable group and in need of attention. The requirements described are referred to aspects, such as mental and social health. The effect of their role as caregiver has an effect on the intense overload for most of them, threatening their physical and mental health. Further research is suggested, as well as implementing programs of attention to this vulnerable group.
\end{abstract}

Key Words: Caregivers, Quality of life, Cancer

\section{INTRODUCTION}

People suffering from chronic diseases, terminal illnesses, senior citizens and the ones that change in assistance by health providers require increasingly less time in hospital, which have led to the need of an informal caregiver (IC) or a relative caregiver. The IC work is not regulated, it has neither schedule nor payment, and caregivers generally do not receive any formal instruction in this regard. They are a care source so as to weak and dependent people, disabled patients and other groups could continue living in their houses or communities Mexico.

*Correspondence: Maria Isabel Peñarrieta de Córdova; Email: pcordoba@uat.edu.mx; Address: Rivas Guillen Nro 600. Cd. Madero, Tamaulipas, 
and avoid being institutionalized. ${ }^{[1]}$ Cancer is among the chronic illnesses that have generated high demand for IC due to its chronic evolution. Many advances have been made in the treatment for cancer; however, many of them still require domiciliary care. ${ }^{[2]}$ That is where IC is key and it is not only difficult and painful at times, but in the long-term both for the patient and caregiver.

In Peru, most cases with cancer are diagnosed in advanced stages, so half of the cases are not able to be surgically explored. Meanwhile, the health of the patients deteriorates and they become more and more dependent on the attention of the $\mathrm{IC}^{[3]}$ for the rest of their lives due to their adaptation to changes. The pressure caregivers bear (the high demand for care, the lack or low social support, and lack of support from health systems) alter significantly their quality of life. Physically, a caregiver faces fatigue, headaches, dyspepsia, dizziness, trouble sleeping, joint pain, unhealthy habits. Psychologically, they suffer from anxiety, and depression. Socially, they find a lack of support groups, financial problems -since their income decreases and their spending increases which lead to an impact on access employment-, limited ability to work or stop working temporarily or permanently, as well as a change in work schedules. Emotionally, they need faith, hope, etc. This is a disadvantage both for the IC and the cancer patients once they are released from hospital. ${ }^{[4]}$ To maintain the IC quality of life, communication it is required, as well as support with the work overload and co-responsibility inadvertently gained that is assumed when caring the patient. Caring for a person with cancer generates dependency on both, changes in their lives at personal, family, work and social levels even a negative impact on their physical and psychological health, physical and emotional overload that may lead the IC to become a patient and abandon the family1.Other factors that could coexist influencing the quality of life of the IC is the income, occupation, education, family type, marital status, gender, age, culture, education, time devoted to care, employment, emotional and physical health, which cause detrimental alterations to the quality of life (QOL) of the IC and therefore on the assisted patient. ${ }^{[5]}$ Studies claim that if the IC suffers from physical, emotional condition, among others, it affects the quality of care offered to cancer patients and thus disrupts the QOL of that patient ${ }^{[2,6-8]}$ likewise, some evidences ${ }^{[9,10]}$ report the social, psychological, physical impact on the QOL and the family as a whole, not only to the IC but also the patient.

\section{MethodS}

\subsection{Study design and setting}

It was a correlational cross-sectional design between the work overload and the quality of life of the IC.

\subsection{Study population and sample}

A non-probabilistic sample was used since the size of the population was unknown, as it is the first study conducted in Lima with these features. It was decided to have a size of 100 participants to apply the statistical technique of correlation according to one of the aims of this study. ${ }^{[11]}$

There were two inclusion criteria: 1) Answer 'Yes' to this question, are you responsible for the care of the patient most of the time? If the answer is 'Yes' people were asked 2) the authorization to participate in the study. Exclusion criteria were: to take care of the patient only at times, to receive a salary for the caring.

The ICs were selected among the ward of Chemotherapy Cancer Services of National Hospital Arzobispo Loayza in Lima, Peru. Inclusion criteria were verified during different schedules (morning and afternoon) asking the person who came with the patient. The total population was 164 caregivers, collected during the months of July to December 2014.

\subsection{Data collection}

Every selected person was surveyed and asked directly. All answers were recorded. Interview lasted about 30 minutes each. All surveys were conducted by senior students of nursing, who received all information and training about the survey with the aim of applying it correctly and avoiding misleading interpretations by people interviewed.

\subsection{Data collection tools and assessments}

The instrument was structured in four parts: Part I: Socio demographic data and aspects of caregiver time and health; Part II: Zarit Rating Scale with 22 items which measure overload of the care. The Scale was adapted to Latin American average for Lizman (2008, Cronbach's alpha of 0.92 quoted in Beltrán $\left.{ }^{[8]}\right)$, where the score is considered less than 47 points: no overload, from 47 to 55 mild overload and more than 55 points as intense overload; Part III: 36 items of the SF-36 (Short Form - 36 Health survey, developed for the study of medical outcomes: medical Outcomes Study, USA 1991), these 36 items are grouped into eight dimensions: physical function, physical role, bodily pain, general health, vitality, social function, emotional role and mental health. Each dimension was structured with a score from 0 to 100 , so that the total score of the scale is the average of the scores of the items that comprise it. Therefore, the highest score for each dimension of the SF-36 is 100 and the lowest zero. The score is directly proportional to the QOF of the patient, and has been used as an outcome in other studies assessing the health of caregivers of cancer patients ${ }^{[12,13]}$ and Part IV: Data related to the patient, using "Barthel Scale or Barthel ADL 
Index" to evaluate dependency levels.

\subsection{Ethical considerations}

Each IC selected signed an informed consent prior to the survey. Likewise it was approved by the Ethics Committee of the University Norbert Wiener and the hospital that participated in this study.

\subsection{Data analysis}

Two statistical techniques were used: descriptive statistics, Previously, the scoring method was used in the 36-Item Short Form Survey according to said instrument. Frequencies were analyzed in categorical variables and their distribution in continuous variables. Subsequently the Spearman correlation was applied since the overload variable is ordinal and the quality of life is continuous to analyze the Relationship between quality of life and overburden of work.

\section{Results}

The average IC sample were adults with an average of 40 years, women in two-thirds $(70 \%)$ with an average of 11 years of schooling. More than a half $(60 \%)$ was close relatives with the caregiver (wife/husband, parents, and siblings) Regarding employment status, more than half (59\%) worked at the time, and of these, most $(78 \%)$ have changed their occupational activity work to take care of the patient (see Table 1).

Table 1. Socio demographic aspects about the Informal Caregiver

\begin{tabular}{lll}
\hline Demographic aspects & F (n:164) & \% (100) \\
\hline Age & $\mu: 40$ & Range: 19-76 \\
Education (years of schooling) & $\mu: 11$ & Range: 1-17 \\
Gender & & \\
Female & 113 & 68.9 \\
Male & 51 & 31.1 \\
Relation with the patient & & \\
Husband/wife & 32 & 19.5 \\
Sibling & 17 & 10.4 \\
Father/Mother & 49 & 29.9 \\
Others(niece, aunt, neighbor, friend) & 66 & 40.2 \\
Socio-economic aspects: & & \\
Currently working & & \\
Yes & 97 & 59.1 \\
No & 67 & 40.9 \\
The IC had to leave the work & & \\
Totally & 43 & 26.2 \\
Partially & 27 & 35.4 \\
The IC is adapted to care activity & 58 & 22.0 \\
No & 36 & \\
\hline
\end{tabular}

Note. IC: Informal caregivers

The finding in Table 2 shows that half of the ICs presented health problems such as trouble sleeping and fatigue (an average of 4-5 points, within a range of 1-10). Almost all (90\%) reported to suffer from no more than three chronic problems, as well as to attend to a doctor less than 10 times a year; however, there was polarization in regard to the medication taken with or without medical indication; the majority $(80 \%)$ did not exercise. Interestingly, on the findings about health perceptions $39 \%$ perceived an average or poor health care compared to last year results, $29 \%$ perceived their health is getting worse than the previous year (see Table 2).

Table 2. Personal characteristics and health perceptions of informal caregivers

\begin{tabular}{|c|c|c|}
\hline Health aspects & F (n:164) & $\%(100)$ \\
\hline \multicolumn{3}{|l|}{ Chronic problems } \\
\hline More than three problems & 17 & 10.4 \\
\hline Less than three problems & 147 & 89.6 \\
\hline \multicolumn{3}{|l|}{ Number of Consultations in the year } \\
\hline Less than 10 & 147 & 89.6 \\
\hline More than 10 & 17 & 10.4 \\
\hline \multicolumn{3}{|c|}{ Medication taken without medical indication } \\
\hline Yes & 84 & 51.2 \\
\hline No & 80 & 48.8 \\
\hline \multicolumn{3}{|l|}{ Did the patient do exercises last week? } \\
\hline Yes & 31 & 19.5 \\
\hline No, not last week & 2 & 0.5 \\
\hline $\begin{array}{l}\text { "The patient do not do exercise regularly, } \\
\text { anyway” }\end{array}$ & 131 & 80.0 \\
\hline \multicolumn{3}{|c|}{ Health perception compared to last year } \\
\hline Much better now than before & 24 & 14.6 \\
\hline A bit better now than before & 17 & 10.4 \\
\hline Almost the same than last year & 76 & 46.3 \\
\hline A bit worse than last year & 39 & 23.8 \\
\hline Much worse than last year & 8 & 4.9 \\
\hline \multicolumn{3}{|l|}{ Current health perception } \\
\hline Excellent & 8 & 4.9 \\
\hline Verygood & 15 & 9.1 \\
\hline Good & 79 & 48.2 \\
\hline Moderate & 62 & 37.8 \\
\hline Poor & 0 & 0 \\
\hline Trouble sleeping & $\mu: 4$ & Range: $1-10$ \\
\hline Fatigue & $\mu: 5$ & $\begin{array}{l}\text { Range: } 1-10 \\
\text { 10: the worst }\end{array}$ \\
\hline
\end{tabular}

Selected people assisted by an IC were all people diagnosed with any cancer, who have come to receive medical care in the aforementioned hospital. The average age of these patients was 59 years old; only one of them was 15 years old, since this is a hospital that mostly caters adults. Most (69\%) were women with some level of dependence on its majority $(66 \%)$. More than a half $(60 \%)$ had moderate to severe dependence. $85 \%$ of ICs referred to perform this role for more than three months; that is, that almost all (87\%) have not yet completed one year in this function. More than half (60\%) reported receiving help to take care of them, half are cohabiting. Half (50\%) did not have help with the housework (see Table 3). 
Table 3. Personal characteristics and care provided by informal caregivers

\begin{tabular}{lcl}
\hline Care aspects & F (n:164) & \% (100) \\
\hline Age of the patient & $\mu: 59$ & Range: 15-90 \\
Gender of the patient & 113 & 68.9 \\
Female & 51 & 31.1 \\
Male & 11 & 6.7 \\
Patient's dependence rate (Barthel ADL index) & \\
<20 points total dependence & 41 & 25.0 \\
20-60 points severe dependence & 53 & 32.3 \\
61-90 points moderate dependence & 16 & 9.8 \\
91-99 points mild dependence & 43 & 26.2 \\
100 points in dependence & 19 & 11.6 \\
Are Informal caregivers helped in household chores? \\
Yes, it is paid & 57 & 34.8 \\
Yes, It is unpaid & 88 & 53.7 \\
No & 25 & 15.2 \\
Period of time as: Informal caregivers $(\mu: 9)$ & 34.8 \\
Less than 3 months & 57 & 36.6 \\
From 3-6 months & 60 & 12.2 \\
From 7-12 months & 20 & \\
Over a year & & \\
\hline
\end{tabular}

The results showed that the majority (74\%) had severe overload (see Figure 1). The areas of highest percentages of overload are fear and dependency of the IC to their family: they feel their family asks for more help than really needed, fear for the future that awaits for their family, they feel that their family depends on them, they think their family expects them to look after the patient as if they were the only people they can count on.

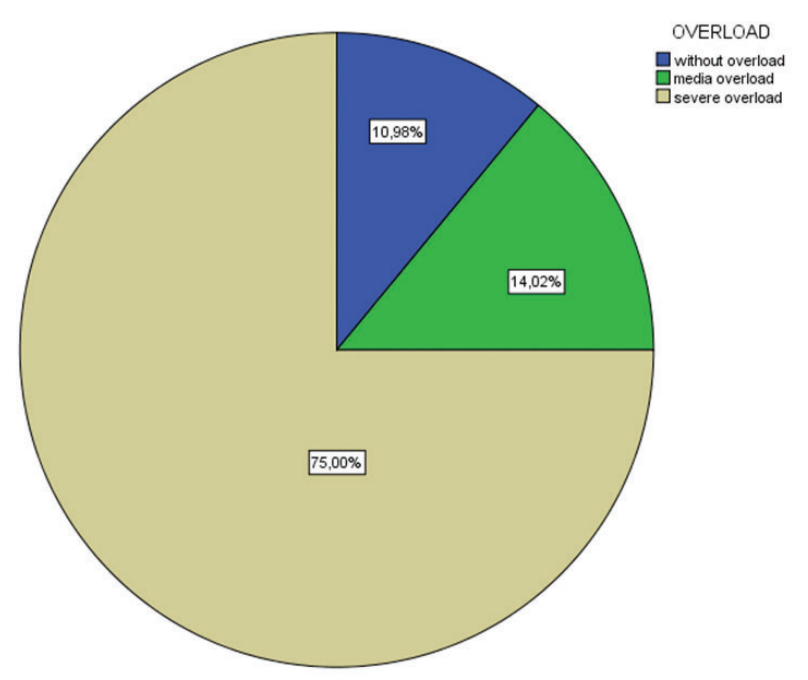

Figure 1. Informal caregivers work overload

Published by Sciedu Press
The results also showed that the time to perform the IC function could not necessarily be understood as an overload, it seems rather the beginning or in the first months where higher overhead rates were evident, although this relationship was not statistically significant $(p=.93)$.

However, there was a relationship between overload and levels of dependence on the caregiver (Spearman $\rho$ : 0.201; $p$ : $0.000)$.

The results of the quality of life in their 8 Dimensions presented an average below 60 in social functions, vitality, mental health and general health (see Table 4).

Table 4. Quality of life of Informal caregivers

\begin{tabular}{lll}
\hline Dimensions(SF36) & Average & Standard deviation \\
\hline Physical Function & 87.95 & 19.216 \\
Physical Role & 72.56 & 39.670 \\
Emotional Role & 70.52 & 40.377 \\
Pain & 77.09 & 21.132 \\
Mental Health & 44.55 & 12.043 \\
Social Function & 56.88 & 19.254 \\
General Health & 45.62 & 13.615 \\
Vitality & 56.85 & 15.725 \\
\hline
\end{tabular}

The results of significant correlation between quality of life and overload are: General health, social functioning and Body pain $(p<.05)$ (see Table 5).

Table 5. Correlation between overload and IC quality of life

\begin{tabular}{lcl}
\hline & Corr. & $(\boldsymbol{p}<\mathbf{. 0 5})$ \\
\hline General Health & -.171 & .029 \\
Social Function & .180 & .021 \\
Body pain & -.183 & .019 \\
Physical function & -.089 & .260 \\
Physical role & -.041 & .603 \\
Emotional role & -.025 & .748 \\
Vitality & -.089 & .259 \\
Mental Health & .027 & .734 \\
\hline
\end{tabular}

\section{Discussion}

The characteristics of caregivers regarding gender and age ranges reaffirm what is found in the literature about women who take on multiple roles at once, including the IC, ${ }^{[14,15]}$ predominated as IC adults with an average age of 40 , similar to other studies. ${ }^{[16-19]}$ However, it is noteworthy the increasingly high number of young adults who take the role of IC, with the implications and consequences that entails, especially in the distribution of tasks, re- organization of roles and economic burden family issues also identified in other studies ${ }^{[17,20]}$ and is corroborated by the findings of this study that almost all (78\%) have necessarily had to change their occupational work to be an IC. 
As the disease progresses, the radical change in their way of life and the fatigue caused by seeing how a family is gradually losing their physical and mental faculties makes them become from a mere supervisor of the patient's activities to whom seeks the most basic care progresses. This study confirms what is stated in other studies, ${ }^{[18,19,21]}$ "primary caregiver syndrome" also known as the "stress in primary caregivers" is a syndrome of emotional exhaustion, depersonalization and low personal accomplishment that - in fact - can occur among people who work with patients in need of serious attention as in the case of cancer. The description of this syndrome is a combination of fatigue, loss of energy, exhaustion and tiredness.

The second aspect, depersonalization, negative change in attitudes towards others, could correspond to both IC and patients with cancer. While depersonalization at moderate levels would be an adaptive response to this same answer, an excessive degree would demonstrate pathological feelings/emotions callously expressed to others, in this study - the others would be apparently healthy relatives or work/study colleagues. This syndrome is similar to what was found in this group of IC in which the most outstanding or above problems are related to sleep difficulties, fatigue, corroborated as mental health problems; other studies also report problems as depression, ${ }^{[22]}$ anxiety ${ }^{[23]}$ and anger. ${ }^{[24]}$ However, many ICs show emotional problems without being necessarily ratified by clinical diagnostic criteria for the mood or anxiety disorder. So it is common the presence of symptoms such as difficulty to fall asleep, as evidenced in the present study, feelings/emotions of hopelessness, worry about the future, among others.

The impact of the IC will also be called the phenomenon of "work overload" by the assumed task, combining several variables:1) Neglect own health, life projects and social life; 2) Family impairment, related to negligent, rabid and manipulative dynamics; 3) Anxiety or frustration due to the lack of training and expertise in caring for patients dependent wholly or parcially on them. ${ }^{[10,20]}$ A higher overload impairs mental, social and physical health of the IC, causing most frequently anxiety and depression ${ }^{[25,26]}$ greater social isolation disorders, worsening family economic situation, ${ }^{[27,28]}$ greater overall morbidity and even increased mortality than in a different overload population. Additionally, the IC tends to avoid or postpone medical aid to the problems of their dependent relative; hence the probability of maintaining most of its own pathologies that become almost "invisible" to the health system. ${ }^{[28]}$ Said aspect in this study is of great concern, as more than two thirds $(75 \%)$ of the IC showed intense overload, reflecting this in the symptoms reported in behaviors as self-medication, avoiding medical care despite health problems.

This finding also confirms the point made by Barron, ${ }^{[21]}$ since it is clear that the high incidence of these overload factors in IC could lead to a less committed patient care and, as a result, abandonment that would entail not only increased demand for health services but also it will cause a poor quality care to these patients. In this study there was found a relation between caregivers' quality of life and overload of work, which confirms the importance of preventing this burden. The most affected dimensions of the IC's quality of life are mental and social dimensions. Those are vital aspects to be considered in interventions by the nurse and the health team.

Results of the exploration between overload and dependency levels showed a meaningful statistical connection; that is, the higher the dependency levels the higher overload of work as found in similar studies. ${ }^{[29,30]}$

\section{Limitations of the study}

Internal restriction: The study cannot be extrapolated to another scope, it needs to be restricted only to the area of study; however, study hypothesis are allowed to be sustained in other fields around the country.

External restriction: It is only possible to collect data in a given time due to the availability of cancer patients with a higher grade of dependency. Likewise, limitation of the study must be considered, as results related to the cancer type and stage are not available; this can lead to a higher demand for health care by the informal caregiver. This is a limiting factor that prevents comprehension of the problem, since it was not possible to monitor in the long-term. Likewise, the cross sectional design of the study will not allow establishing any causality between burden and quality of life, but relating both factors and quantify the magnitude of the effect. However, the relation is unlikely to be different to this result, as it would indicate that the greater the burden the greater the possibility of a deficient quality of life, which is less plausible provided the physical and psychological requirements needed to take care of a patient.

\section{Conclusions}

The results of this study describe the caregivers group of people with cancer as a vulnerable group and in need of attention.

(1) Consider the socio-demographic characteristics: being a woman, being average age 40 , and having quit the last occupational activity to take the role of an IC. Although you cannot change these characteristics that are considered risk factors for health, at least they can be identified in a timely manner to prevent health risks 
through timely interventions.

(2) The needs described in this vulnerable group are primarily related to their mental and social health. Results showed a decline in quality of life in these dimensions (fatigue, sleep disturbance, lack of energy).

(3) The effect of the caregiver role results in work overload to most of them, threatening their physical and mental health.

(4) It is found a relation between overload and the decline in quality of life. This is a vital factor to be considered by health caregivers.
The results suggest further research is needed, as well as studies with a genre perspective, longitudinal and causal designs, along with an implementation of care programs for this vulnerable group, prioritizing key aspects to improve mental and social health. It is vital to consider the work overload in this vulnerable group, look for strategies to collaborate more with their families, especially when the patient has a higher level of dependency.

\section{CONFLICTS OF INTEREST Disclosure}

The authors declare that there is no conflict of interest.

\section{REFERENCES}

[1] Moncada-García E, Domínguez-Guedea MT, Reguera-Torres ME, et al. Aspectos Psicológicos de Cuidadores Aassociados ao Apoio Familiar na Aderência Terapêutica de Pacientes Diabéticos. Revista Brasileira em Promoção da Saúde 20102348-55. Available from: http://uabj.redalyc.org/articulo. oa?id=408169 74008. Date of reference: 10 December 2015.

[2] Wadhwa1 D, Burman D, Swami N, et al. Quality of life and mental health in caregivers of outpatients with advanced cancer. PsychoOncology. 2013; 22: 403-410.

[3] Salazar MR, Regalado-Rafael R, Navarro JM, et al. The role of the National Institute of Neoplastic Diseases in the control of cancer in Peru. Rev Perú Med Exp Salud Pública. 2013 Mar; 30(1): 105-12. PMid:23612822.

[4] Alfaro-Ramírez O, Morales-Vigil T, Vázquez-Pineda F, et al. Ansiedad y depresión en cuidadores primarios de pacientes con dolor crónico y terminales. Rev Med Inst Mex Seguro Soc. 2008; 46 (5): 485-494. PMid:19241656.

[5] Espinosa A. Sentido de coherencia y consecuencias del cuidado informal: una revisión sistemática. Tesis de grado.Universidad de Jaén. Facultad de Ciencias de la Salud. España. 2014.

[6] Yang X, Hao Y, George SM, et al. Factors associated with healthrelated quality of life among Chinese caregivers of the older adults living in the community: a cross-sectional study. Health and Quality of Life Outcomes. 2012; 10: 143. http://dx.doi.org/10.1186 /1477-7525-10-143

[7] Kim Y, Ryn M, Jensen RE, et al. Effects of gender and depressive symptoms on quality of life among colorectal and lung cancer patients and their family caregivers. Psycho-Oncology. 2015; 24: 95105. PMid:24831223. http://dx.doi.org/10.1002/pon. 3580

[8] Nayak MG, George A, Vidyasagar MS, et al. Quality of life of family caregivers of patients with advanced cancer. Journal of Nursing and Health Science. 2014; 3(2): 70-75.

[9] Duarte E, Santos J, Aguirrezabal A, et al. EscaladaDeterioro de la calidad de vidaencuidadoresfamiliares de pacientes con discapacidadpor ictus: unaentidad a considerar. Elsevier. 2010; 25(6): 356-364.

[10] Beltrán A, León R. Sobrecarga del cuidador y calidad de vida en pacientes con Parkinson del HBVLE EsSalud Trujillo. Tesis para optar el título de Licenciado en Psicología. Universidad Cesar Vallejo, Trujillo, Perú. 2009.

[11] ARIAS, Fernando: Metodología de Investigación, México, Ed. Trillas. 2007: 576. ISBN 978-968-24-7993-9.

[12] Ware JE, Kosinski M, Gandek B, et al. The factor structure of the SF-36 Health Survey in 10 countries: results from the IQOLA Project.
International Quality of Life Assessment. J Clin Epidemiol. 1998; 51(11): 1159-1165.

[13] Hughes SL, Weaver FM, Giobbie-Hurder A, et al. Effectiveness of team-managed home-based primary care: a randomized multicenter trial. JAMA. 2000; 284(22): 2877-2885. http://dx. doi .org/10. $1001 /$ jama. 284.22.2877

[14] Sánchez B. La experiencia de ser cuidadora de una persona en situación de enfermedad crónica. Investigación y Educación en Enfermería. 2001; 19(2): 36-51.

[15] Ospina DE, Soto CP. Entre el rito y la rutina: el rol de cuidadora en las mujeres de Medellín. Investigación y Educación en Enfermería. 2001; 19 (2): 58-65.

[16] Barrera L, Pinto N, Sánchez B. Habilidad de cuidado de cuidadores familiares de personas con enfermedad crónica: comparación de géneros. Actualizaciones en enfermería. 2006; 9(2): 9-13.

[17] Barrera-Ortiz L, Carrillo-González Gloria y Chaparro-Díaz L, PintoAfanador N. y Sánchez-Herrera B. Soporte social con el uso de TIC's para cuidadores familiares de personas con enfermedad crónica. Rev Salud Pública. 2011; 13 (3): 446-457.

[18] Tripodoro V, Velosov, Lanos V. Sobrecarga del cuidador principal de pacientes en cuidados paliativos. Publicación del Instituto de Investigaciones Gino Germani Facultad de Ciencias Sociales. Universidad de Buenos Aires. 2015; 17: 307-330.

[19] Garcia BC. Estudio cualitativo perfil del cuidador primario, sus estilos de afrontamiento y el vinculo afectivo con el paciente oncológico infantil. Tesis Doctoral. Universidad RamonLluy, Facultad de Sicologia,Cataluña, España. 2011.

[20] Meecharoen W, Yupapin S, Supreeda M, et al. Northouse. Factors Influencing Quality of Life among Family Caregivers. Pacific Rim Int J Nurs Res. 2013 October - December: 304-315.

[21] Barrón A. Desgaste Físico y Emocional del Cuidador Primario en Cáncer. 2009; Cancerología 4: 39-46.

[22] Alvarado-Aguilar S, Ochoa-Carrillo FJ. La Psicooncología sumando esfuerzos; un compromiso. GAMO. 2011; 10(3): 121-122.

[23] Caqueo-Urízar A, Segovia-Lagos P, Urrutia-Urrutia Ú, et al. Impacto de la relación de ayuda de cuidadores primarios en la calidad de vida de pacientes con cáncer avanzado. PSICOONCOLOGÍA. 2013; 11(1): 95-108.

[24] Schoenmakers B, Buntinx F, Delepeleire J. Supporting Family Carers of Community-Dwelling Elder with Cognitive Decline: A Randomized Controlled Trial. International Journal of Family Medicine. 2010; Article ID 184152, 10 pages. http://dx.doi .org/10.1155/201 $0 / 184152$ 
[25] Mendoza-Suárez G. Síndrome de sobrecarga en familiares encargados del cuidado de pacientes con enfermedad neurológica crónica. RevSocPeruMed Interna. 2014; 27 (1): 12-18.

[26] Rubira1 EA, Marcon1 SR, Belasco AGS, et al. Burden and quality of life of caregivers of children and adolescents with chemotherapy treatment for cancer. Acta Paul Enferm. 2012; 25(4): 567-73.

[27] Wisniewski S, Belle SH, Coon DW, et al. The Resources for Enhancing Alzheimer's Caregiver Health (REACH): project design and baseline characteristics. Psychol Aging. 2003; 18: 375-84. PMid:14518801.http://dx.doi.org/10.1037/0882-7974.18
.3 .375

[28] María del Mar GC, Inmaculada MR, Gracia MN. El impacto de cuidar en la salud y la calidad de vida de las mujeres. Gac Sanit. 2004; 18(Supl 2): 83-92.

[29] Calero RM, Fernández C, Roa JM. Cuidador informal de personas mayores dependientes y estrés percibido: intervención psicoeducativa. Scientia. 2009; 14(1): 9-19.

[30] Peñaranda AP. El cuidador primario de familiares con dependencia: Calidad de vida, apoyo social y salud mental. Tesis. Universidad de Salamanca Facultad de Medicina. Salamanca, Mayo del. 2006. 